Scientific Journal of Hamadan Nursing \& Midwifery Faculty - ISSN 2008-2819

\title{
The Effects of Teaching the Communication Skills to Patients Through Role-Playing Method on Nursing Students' Self-Efficacy
}

\author{
Fatemeh Karbasi ${ }^{1}$, Mahnaz Khatiban ${ }^{2 *}$, Alireza Soltanian ${ }^{3}$
}

1. Instructor, Department of Medical Surgical Nursing, Faculty of Nursing and Midwifery, Hamadan University of Medical Sciences, Hamadan, Iran

2. Associate Professor in Nursing, Mother \& Child Care Research Center, Hamadan University of Medical Sciences, Hamadan, Iran

3. Associate Professor in Biostatistics, Department of Biostatistics, School of Public Health, Hamadan University of Medical Sciences, Hamadan, Iran

\begin{tabular}{|c|c|}
\hline Article Info & ABSTRACT \\
\hline $\begin{array}{l}\text { Received: 2018/03/08; } \\
\text { Accepted: 2018/06/27; } \\
\text { Published Online: 2018/08/04 } \\
\text { DOI: }\end{array}$ & $\begin{array}{l}\text { Introduction: Teaching the professional communication skills can be effective } \\
\text { in developing the learners' self-efficacy. In the patients' training with communication } \\
\text { skills, the active and student-centered learning methods, such as role-playing, are } \\
\text { emphasized. Therefore, this study was run to determine the effects of applying the } \\
\text { role-playing method to communication education on the self-efficacy and } \\
\text { communication skills of nursing students. }\end{array}$ \\
\hline
\end{tabular}

$\underline{10.30699 / \mathrm{sjhnmf} .26 .6 .357}$

Original Article

Use your device to scan and read the article online

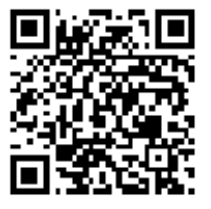

Methods: This controlled before-after quasi-experimental study was conducted in Hamadan University of Medical Sciences in 2015. Out of 15 student groups, four groups were randomly assigned to the role-playing $(n=32)$ and four groups to the routine $(n=32)$. Sherer's self-efficacy questionnaire was completed by students at the beginning and end of clinical education. Patient-nurse communication program training through role-playing method was implemented during the interval period. Data analysis was run using SPSS16 by statistical tests at $95 \%$ confidence level.

Results: Students in the role-playing group were compared to the conventional group in terms of the individual characteristics $(P>0.05)$. At the baseline, the control group had higher self-efficacy than those in the role-playing group $(P<0.05)$. But after the intervention, analysis of covariance showed that the significant progress was only made in the role-playing students' self-efficacy compared to the control group when baseline score differences were controlled $(P<0.001)$.

Conclusion: Using an active role-playing method can lead to self-efficacy of undergraduate nursing students in comparison with the traditional method.

Keywords: Education, Role-Play, Nurse-Patient relationship, Self-Efficacy, Nursing students

\section{How to Cite This Article:}

karbasi F, khatiban M, Soltanian A. The Effects of Teaching the Communication Skills to Patients Through Role-Playing Method on Nursing Students' Self-Efficacy. Sci J Hamadan Nurs Midwifery Fac. 2019; 26 (6) :357-365 


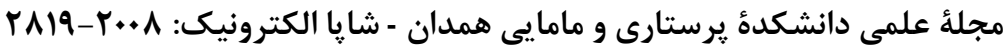

مقالأ يزوهشى

تأثير آموزش مهارتهاى ارتباط با بيمار به روش ايفاى نقش بر خودكار آمدى دانشجويان يرستارى

فاطمه كرباسى'، مهيناز خطيبان "َّ، عليرضا سلطانيان '

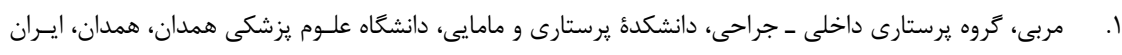

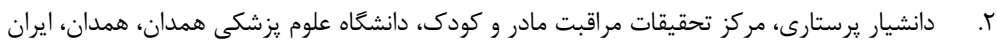

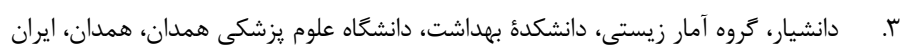

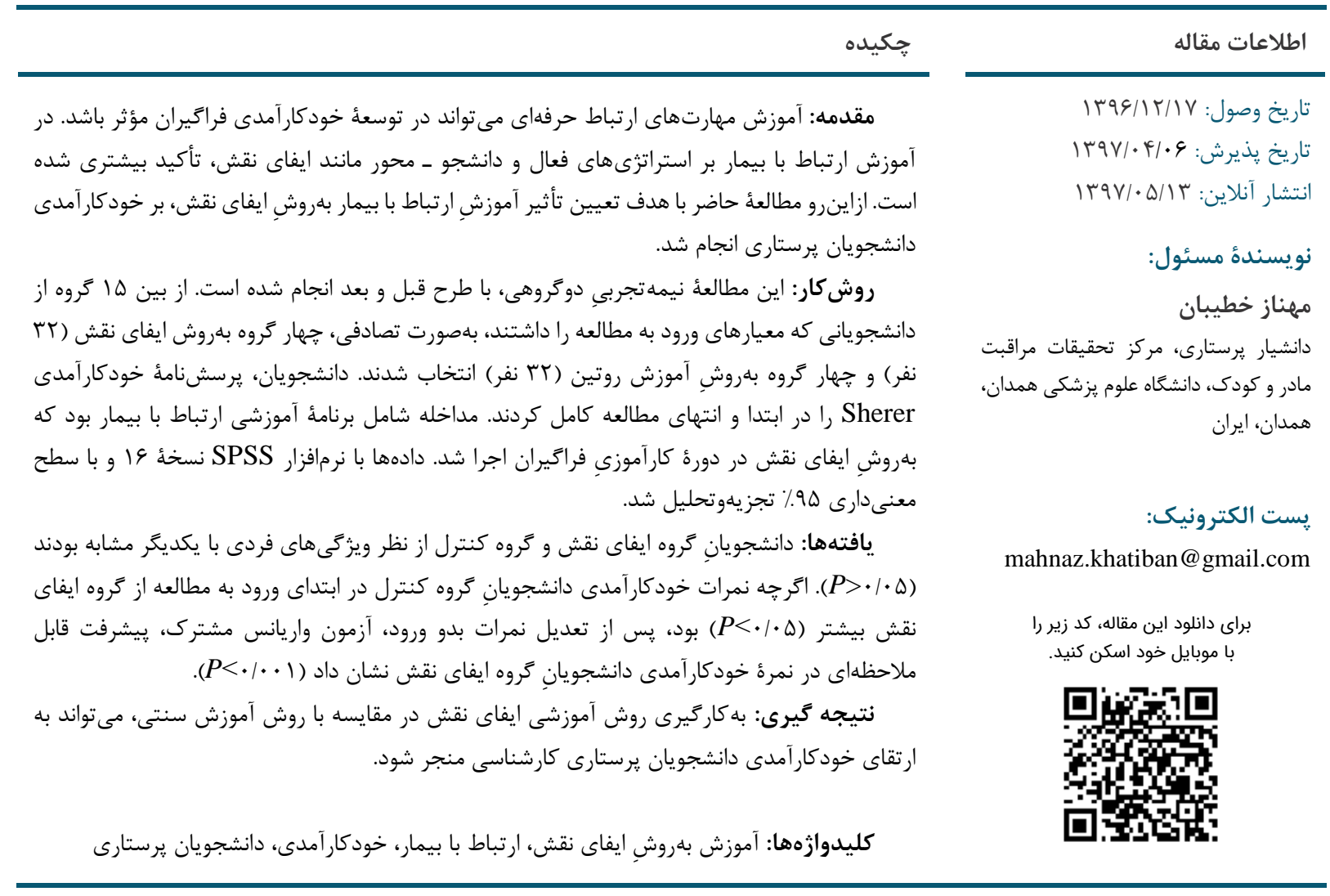

مقدمه - 20 - مقد

ارتقاى صلاحيت و توانايى يرستاران در ارائهُ مراقبت، سرلوحأ

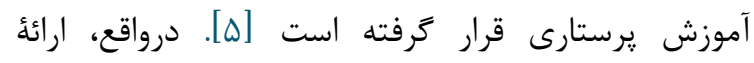
مراقبتهاى با كيفيت و ايمن فقط در يرتو برقرارى ارفئه ارتباط

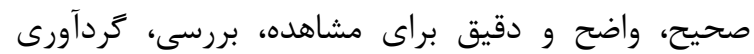

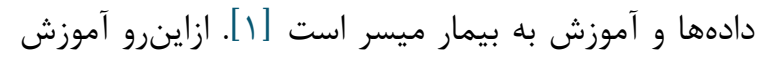

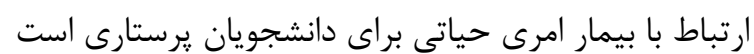

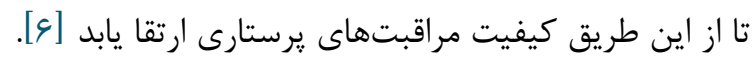
دانشجويان يرستارى بايد در طول تحصيل ارتباطات حرفهاى

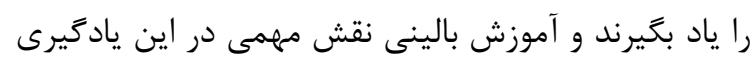

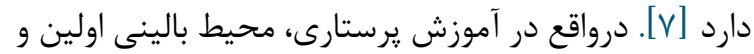

برقرارى ارتباط، مهارتى كليدى در ارائٔ مراقبتهاى

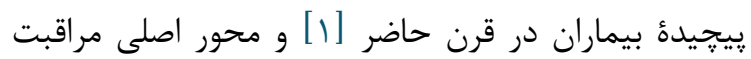

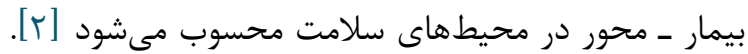
بسيارى از مراكز مراقبت سلامت روشهايى براى افرايطايش

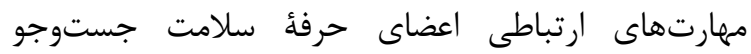

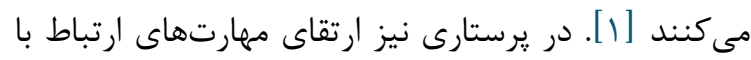

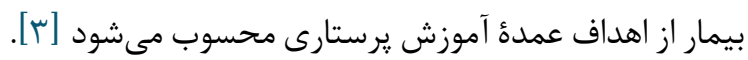

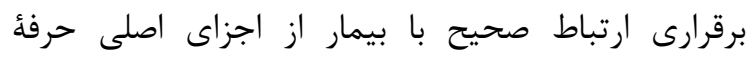

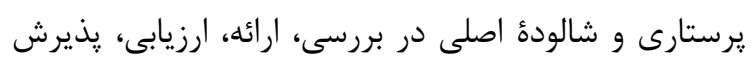

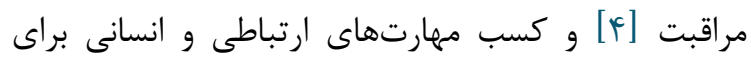




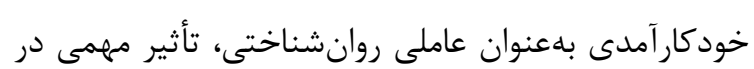

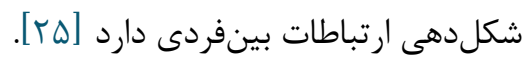

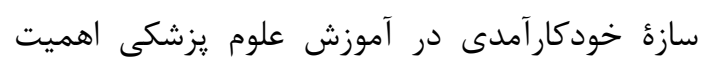

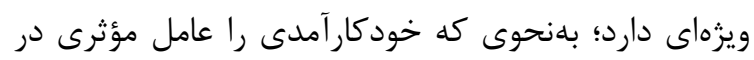

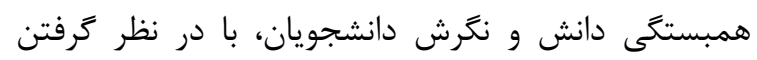

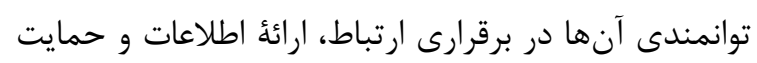

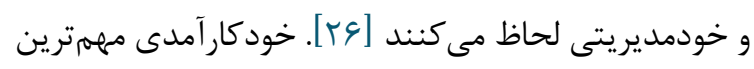

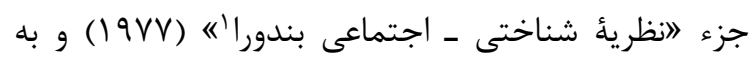
معناى احساس كفايت و توان دستيابى به اهداف آنداف است.

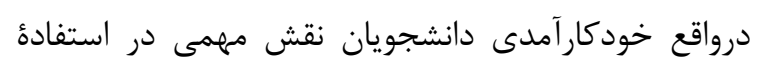

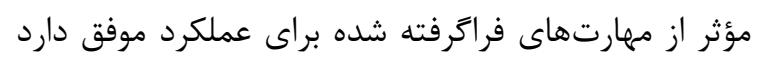

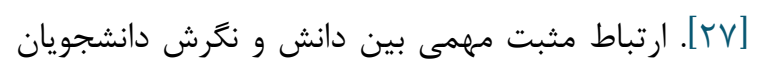

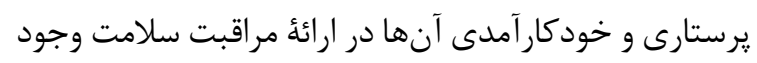

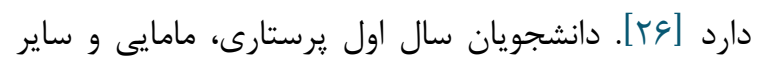

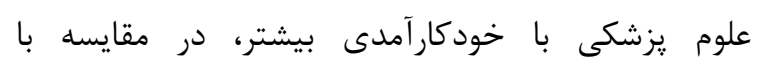
دانشجويانى كه خودكار آمدى كمترى دارندي

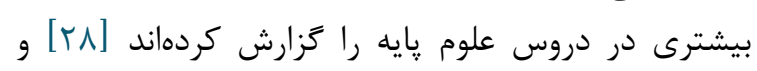

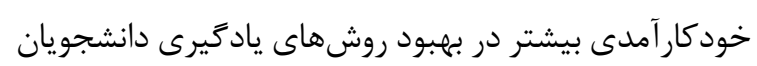

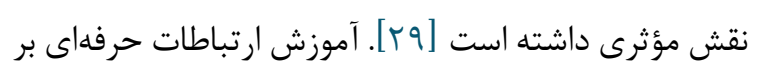

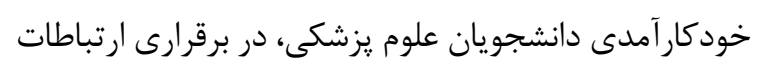

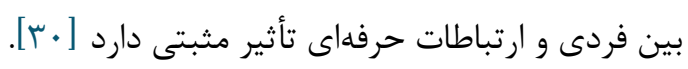

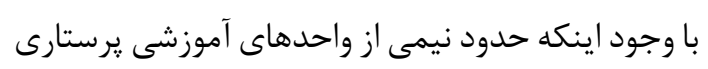

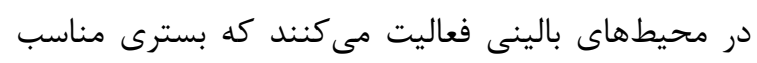
براى كسب مهارتهاى ارتباطى است، هنوز خلاء و ضعائ فئف

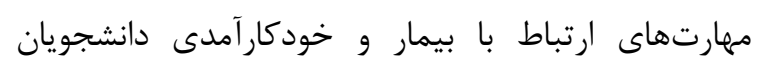

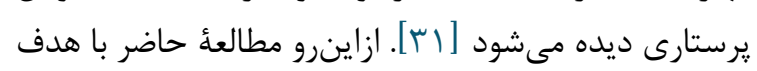

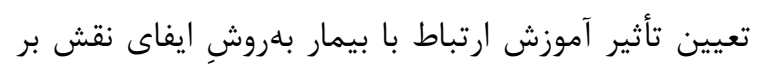

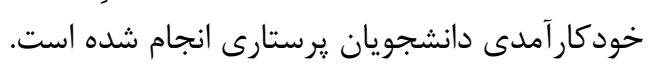

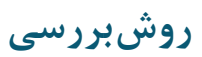

اين يزوهش مطالعه نيمهتجربي دو تروهى با طرح

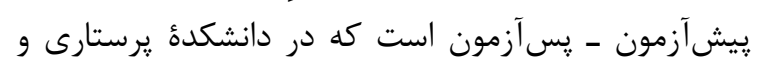

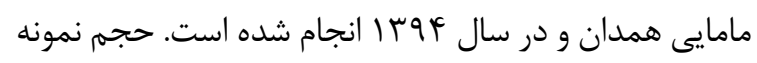

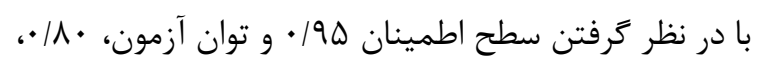

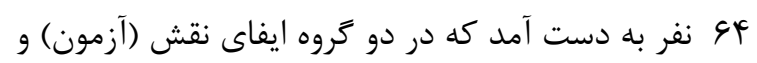

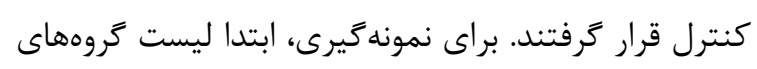

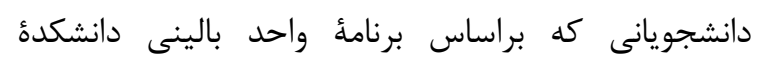
يرستارى و مامايى دانشعاه علوم يزشكى همدان، معيارهاني
مناسبترين مكان براى يادكيرى مهارتهاى ارتباط حرفهاى

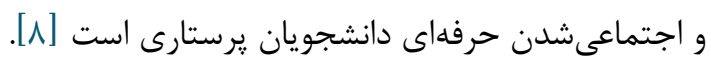

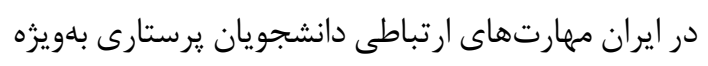

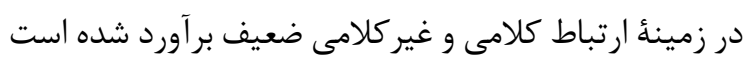

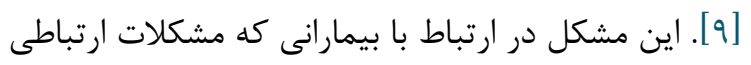

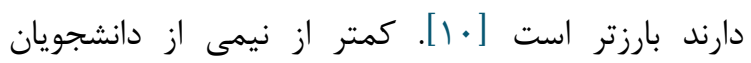

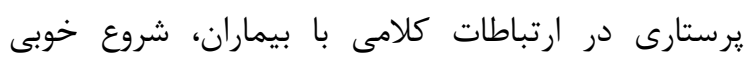

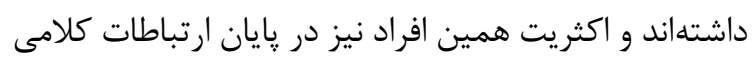

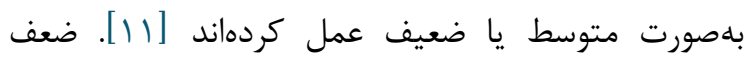

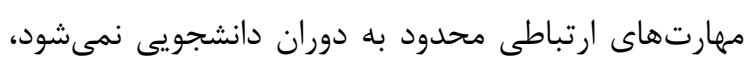

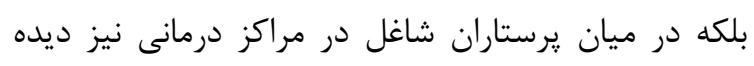

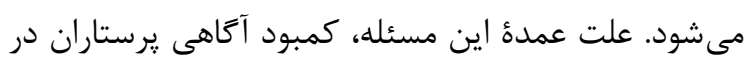

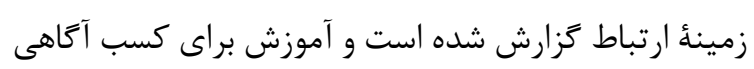

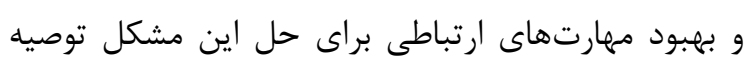

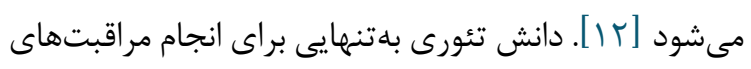

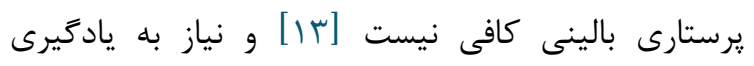

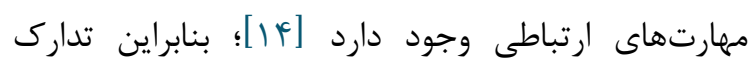

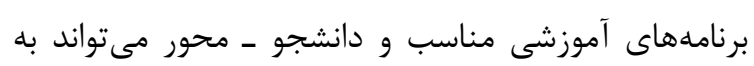

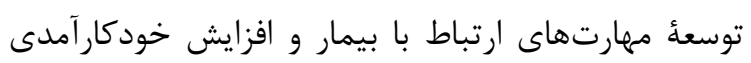

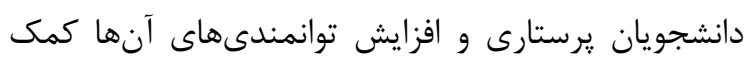

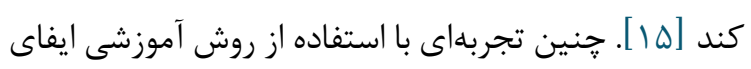

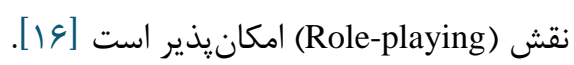

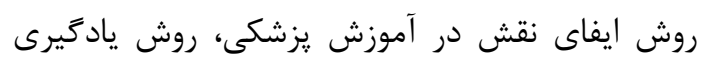

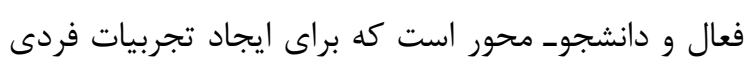

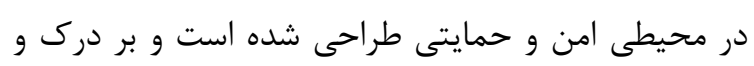

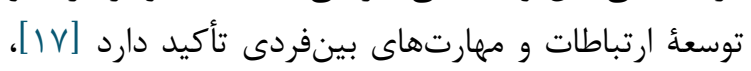
يكى از مؤثرترين روشهاى آموزشى فعال در ياد مَيرى حيطه

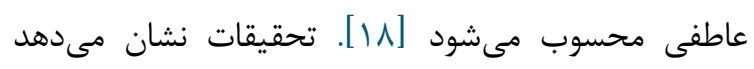

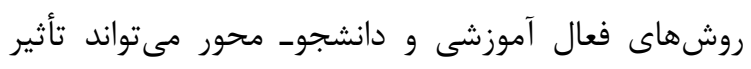

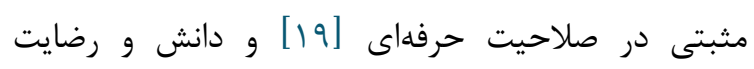

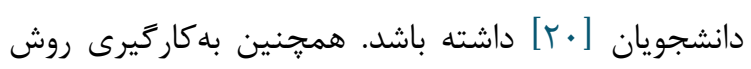

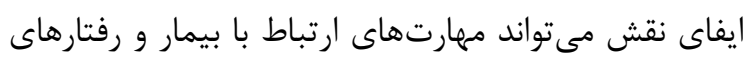

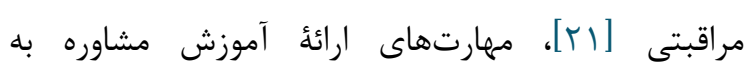

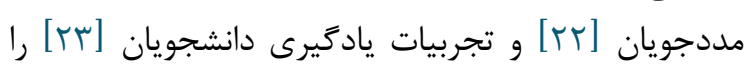

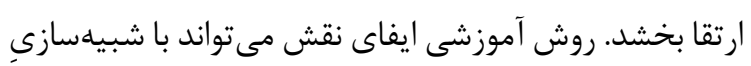

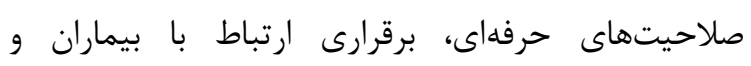

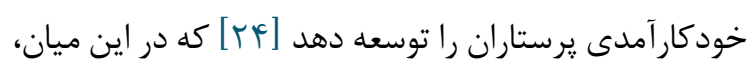

\section{${ }^{1}$ Social Cognitive Theory}

دورة צY شمارة 9 - بهمن و اسفند VY I I 
ايفاى نقش دوباره تكرار شد. سيس بحث و ارزشيابى

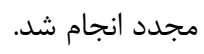
تعميم و ارائٔ تجارب به موقعيتها و كسان ديكر: با هدف

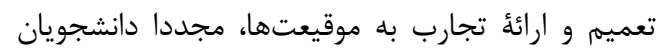
يرسشنامة خودكار آمدى را كامل كردند.

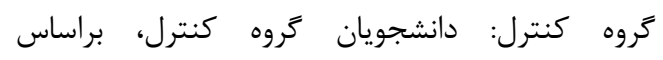
$\wedge$ برنامهريزى واحد بالينى دانشكدة يرستارى و و مامايیى

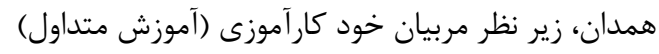

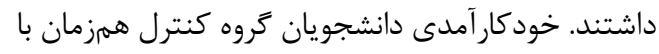

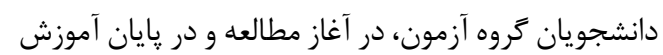

$$
\text { بالينى، ارزيابى شد. }
$$

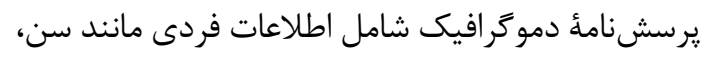

جنس، قوميت، وضعيت تأهل، داشتن كار دانشجويى و و

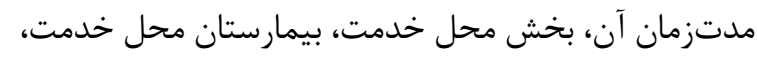

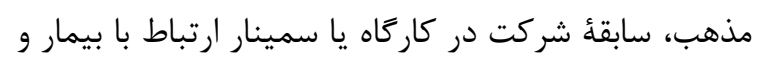

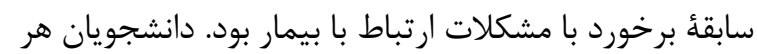

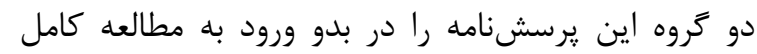

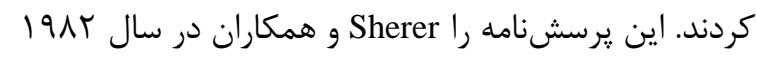
طراحى كردهاند و عبارات آن براى اندازهكيرى خودكار آمدى ونى

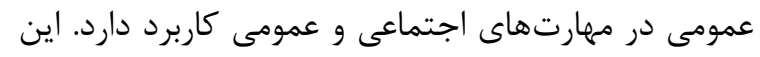

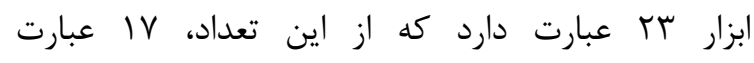

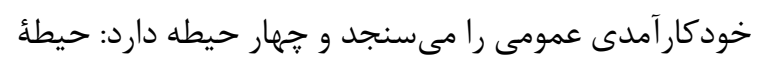

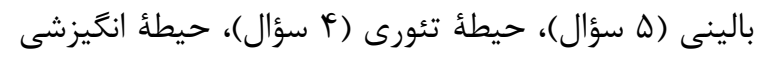

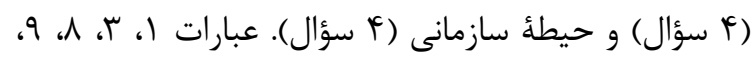

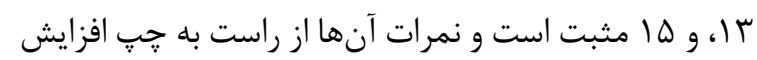

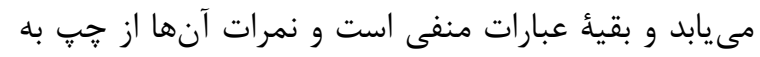

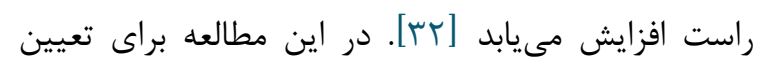

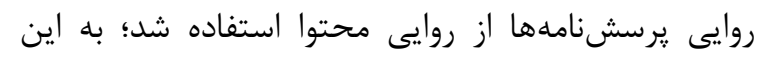

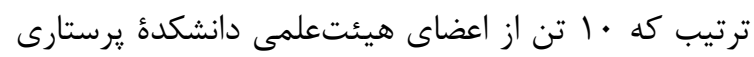

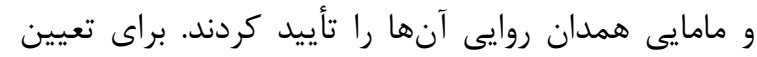

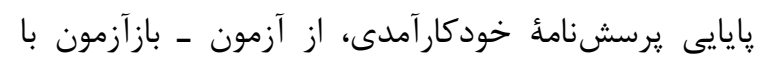

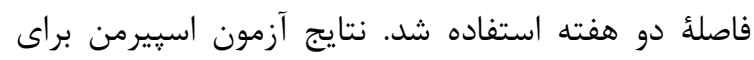

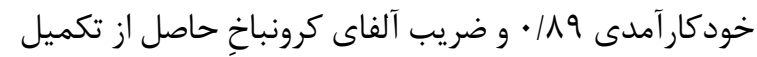

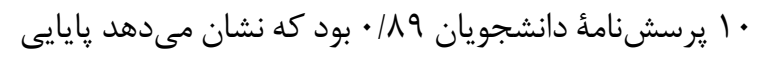

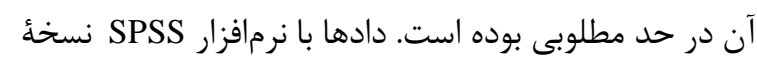
19 انجزيهوتحليل شد. در اين بخش از آز آزمونهاى آمارى

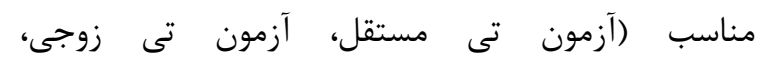

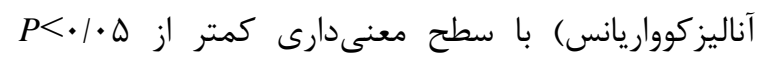

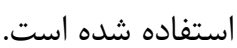

يزوهش را داشتند، تهيه شد. معيارهاى ورود عبارت بود از:

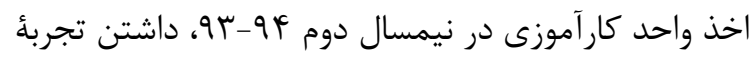

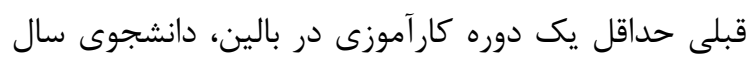

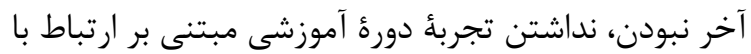

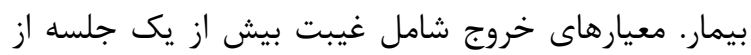

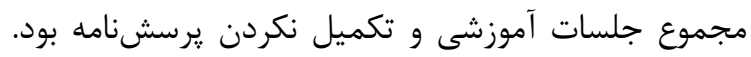

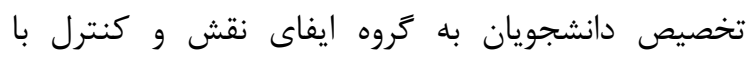

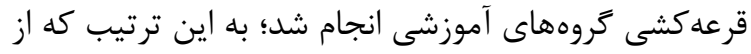

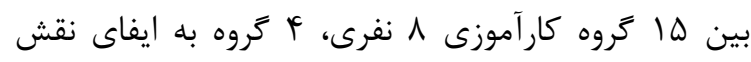

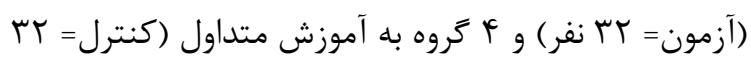
نفر) اختصاص يافتند و در مجموع ثلو دانشجو در مطالعه شركت داده شدند. مداخله حدود جهار ماه طول كشيد. ابزار

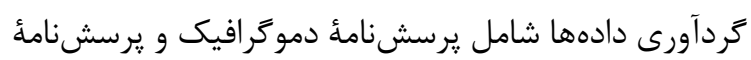

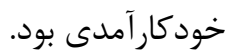

روش اجراى مداخله: براى كروه ايفاى نقش، برنامهٔ

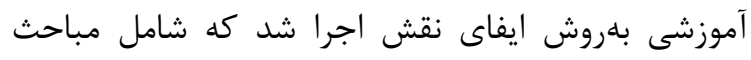

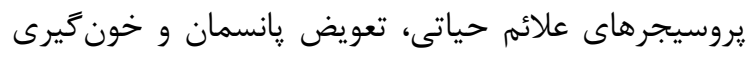

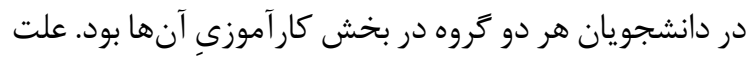

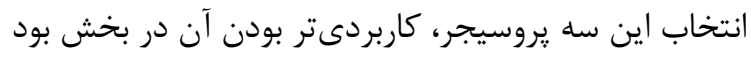

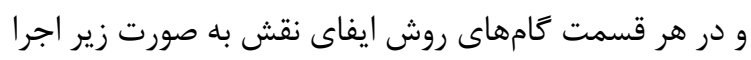

1. آمادكى گروه: ابتداى روز اول كارآموزى در بخش، اهداف

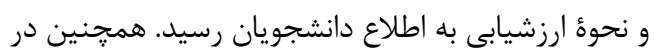

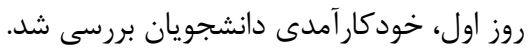

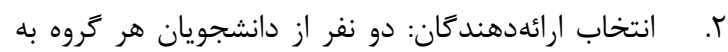

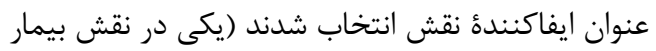

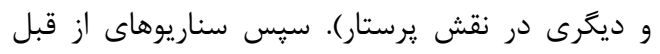

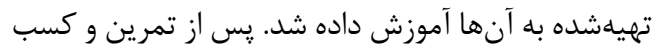
آمادكى در حضور مربى و تأييد او، آمادئ ارائئ ايفاى نقش آنش

شدند. صحنهآرايى: اتاق يراتيك دانشكدة يرستارى بلعنوان

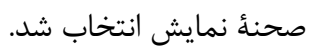

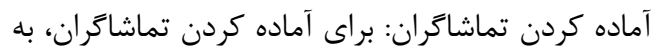

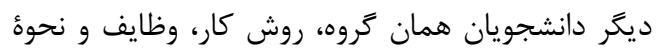
يرسيدن سؤالات و بحث توضيح داده شدان

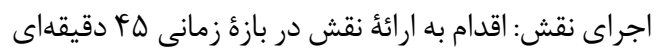
در اتاق يراتيك شد.

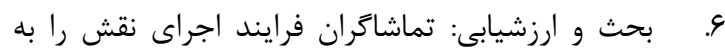

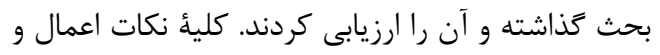


از مداخله، بهنحو معنىدارى متفاوت بود. ازاينرو براى

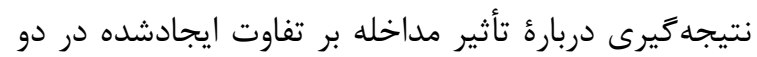

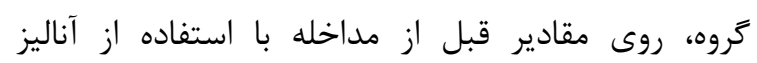

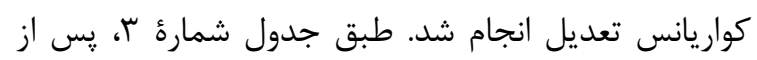

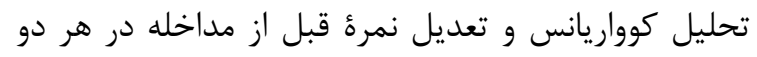

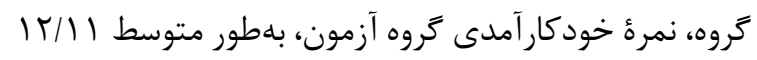

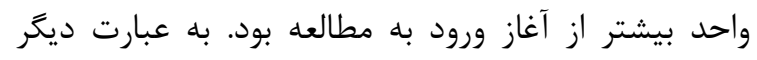

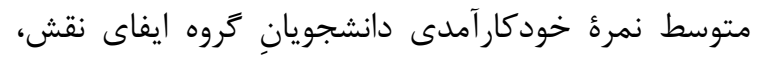

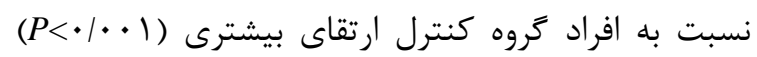

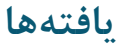

مشخصات فردى دانشجويان شركت كننده در يزوهش به به

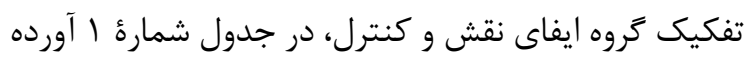

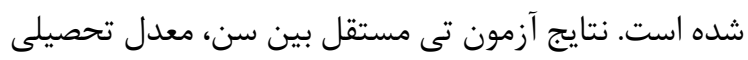

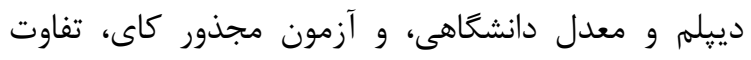

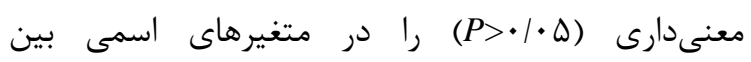
دانشجويان دو كروه نشان نداد.

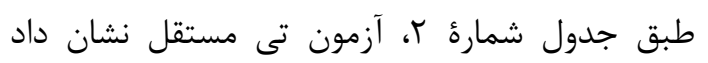

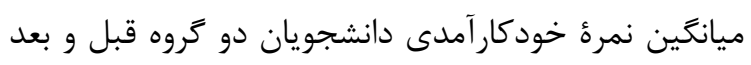

$$
\text { يافته است. }
$$

جدول شماره ا. خصوصيات دموكر افيك و يايئ واحدهاى يُروهش به تفكيك كروههاى ايفاى نقش و كنترل

\begin{tabular}{|c|c|c|c|}
\hline 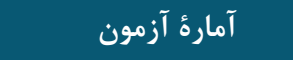 & 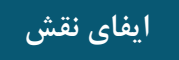 & 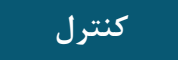 & 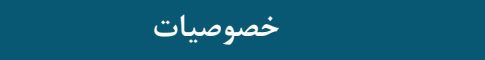 \\
\hline${ }^{a} \mathrm{t}=\cdot / \cdot \wedge r, P=\cdot / 9 r \Delta$ & $r I / \wedge F \pm I / A V$ & $r \mid / \Lambda \Lambda \pm 1 / l$ & سن / سال (انحراف استاندارد士ميانگين) \\
\hline $\mathrm{a}_{\mathrm{t}}=\cdot / \cdot 9 \mathrm{r}, P=\cdot / 9 r q$ & $\mid V / G Y \pm I / \Delta V$ & $|V / \varepsilon| \pm 1 / 1 V$ & معدل دييلم (انحراف استاندارد士ميانگين) \\
\hline${ }^{a} \mathrm{t}=1 / v \cdot v, P=\cdot / \cdot q r$ & $\mid \Delta / r q \pm 1 / 1 \wedge$ & $\mid \Delta / 9 \varphi \pm 1 / 4 \Delta$ & معدل دانشخاهى (انحراف استاندارد士ميانگين) \\
\hline \multirow{4}{*}{${ }^{\mathrm{b}} \mathrm{X}^{2}=r / r \mu r, P=\cdot / r \cdot r$} & & & 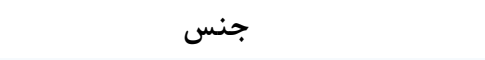 \\
\hline & $(\omega \cdot) \backslash \varepsilon$ & $(r \mid r)) \cdot$ & 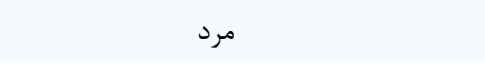 \\
\hline & $(\omega \cdot) \mid \varepsilon$ & $(\varepsilon N / \Lambda) Y T$ & 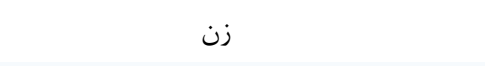 \\
\hline & & & وضعيت تأهل \\
\hline \multirow{3}{*}{${ }^{c} X^{2}=r / 9 \uparrow r, P=\cdot / 199$} & $(99 / 9))_{1}$ & $(\lambda F / \mathcal{F}) Y V$ & 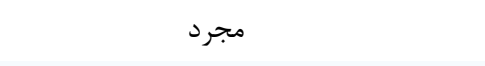 \\
\hline & $(\Gamma / 1) 1$ & $(\mid Q / 9) \Delta$ & متأهل \\
\hline & & & نوع دييلم \\
\hline \multirow{3}{*}{${ }^{c} X^{2}=1 / F F F, P=\cdot / F r q$} & $(\lambda F / F) Y V$ & $(9 \mu / \wedge) \mu \cdot$ & 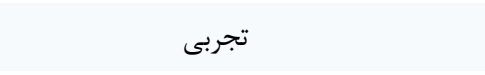 \\
\hline & $(\mid \Delta / \varphi) \Delta$ & $(G / T) Y$ & 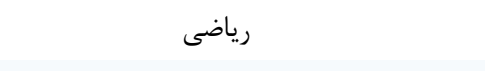 \\
\hline & & & سابقهُ كار بهعنوان يرسنل يرستارى \\
\hline \multirow{3}{*}{${ }^{\mathrm{c}} \mathrm{X}^{2}=1 / \cdot 19, P=1$} & $(\Gamma / 1) 1$ & $(\cdot) \cdot$ & بله \\
\hline & I & (1) ( & خير \\
\hline & & & سابقة كار دانشجويى \\
\hline \multirow{3}{*}{${ }^{\mathrm{c}} \mathrm{X}^{2}=1 / \cdot 19, P=1$} & $(\Gamma / 1))$ & $(\cdot) \cdot$ & بله \\
\hline & $(१ \& / 9))_{1}$ & re) & خير \\
\hline & & & سابقهُ شركت در كاركاه يا سمينار \\
\hline \multirow{2}{*}{${ }^{c} \mathrm{X}^{2}=1 / \cdot 19, P=1$} & $(\Psi / 1))$ & $(\cdot) \cdot$ & بله \\
\hline & $(9 ६ / 9))^{m}$ & r & خير \\
\hline
\end{tabular}

$\mathrm{a}=\mathrm{t}$-test

$\mathrm{b}=$ squate-chi

$\mathrm{c}=$ Fisher's exact test 
جدول شماره r. مقايسهُ نمره خودكار آمدى در دو كروه كنترل و ايفاى نقش، قبل و بعد از مداخلهُ آموزشى

\begin{tabular}{|c|c|c|c|c|c|}
\hline \multirow[t]{2}{*}{$P$-value } & \multirow[t]{2}{*}{ df } & \multirow[t]{2}{*}{ Paired t-test } & بعد (تعداد=fF نفر) & قبل (تعداد=fF نفر ) & \multirow{2}{*}{ خودكار آمدى } \\
\hline & & & Mean \pm SD & Mean \pm SD & \\
\hline$\cdot / 1 F^{\mathrm{F}}$ & r & $1 / 49$ & $\langle\| / / \Delta \pm \varepsilon / r \Delta$ & $r q / g r \pm V / V I$ & كنترل (rr دانشجو) \\
\hline \multirow[t]{2}{*}{$<\cdot|\cdot \cdot| *$} & r & $1 \cdot / \mathrm{VA}$ & $\Delta r / / \Delta \pm \Delta / \mathcal{E} V$ & $r \Delta / V I \pm \& / \varepsilon r$ & 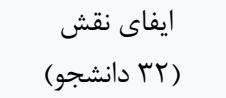 \\
\hline & & & $\begin{array}{c}\mathrm{df}=\boldsymbol{g r}, P<\cdot / \cdot \cdot 1 \\
\mathrm{t}=-\mathrm{V} / \mathcal{F} \wedge\end{array}$ & $\begin{array}{c}d \mathrm{df}=q T d P=\cdot / \cdot r r \\
\mathrm{t}=-r / / V\end{array}$ & دو گروه مستقل \\
\hline
\end{tabular}

جدول شمارهُ با. مقايسُٔ نمرهُ خودكار آمدى در دو كروه كنترل و ايفاى نقش در دو مرحلئ اندازهَيرى

\begin{tabular}{|c|c|c|c|c|}
\hline$P_{-}$value & درجئ آزادى & خطاى استاندارد & ضرايب ركرسيونى & يار امتر \\
\hline$<\cdot / \cdot \cdot 1$ & 1 & $4 / \cdot 1$ & ५ /१५ & عرض از مبدأ \\
\hline$<\cdot 1 \cdot \cdot 1$ & 1 & $1 / \cdot 91$ & $|r /| \mid$ & كروه (مداخله) \\
\hline$\cdot 1 \cdot \cdot \Delta$ & 1 & l/kF & • & نمره خودكار آمدى قبل از مداخله \\
\hline
\end{tabular}

مهارتهاى ارتباط بيمارمحور بهصورت ايفاى نقش، تعداد

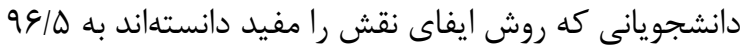

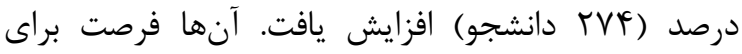

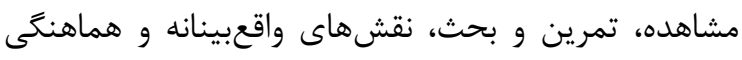
نقش با جنبdهاى ديگر برنامئ درسى را بهعنوان جنبه بهاى مفيد روش ايفاى نقش كزارش كرده بودند و جنبه بهاى

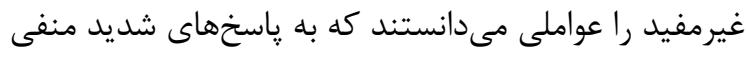

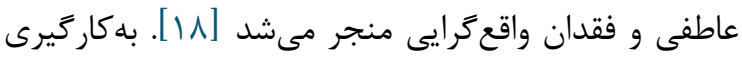
روش ايفاى نقش در كار گاه آموزشى جهار ساعته توانست بلهنو جشمخيرى بر عملكرد و يادگيرى دانشجويان

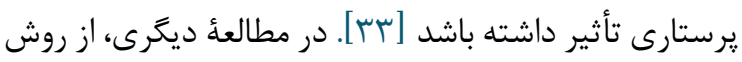
ايفاى نقش براى بهبود اثربخشى ارتباط ميان مراقبان بيمار

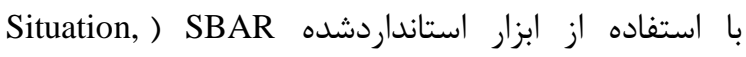
،(Background, Assessment, and Recommendation F. نشان داد دانشجويانى كه علاوه بر سخنرانى، تمرينى دقيقهاى با روش ايفاى نقش داشتهاند، نسبت به كسانى كه فقط بهروش سخنرانى آموزش ديده بودند، دانش برقرارى دي روسي

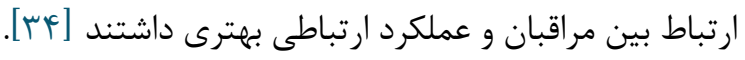

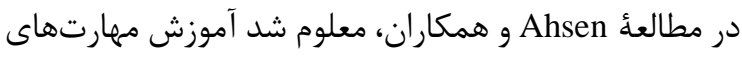
ارتباطى دانشجويان از طريق ويديو و ايفاى نقش در تركيب

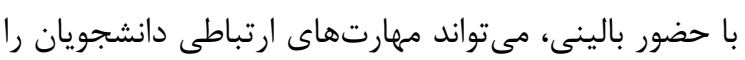

دورة צY شمارة 9 - بهمن و اسفند
يزوهش حاضر نشان داد آموزش ارتباط با بيمار بلهروشِ ايفاى نقش، مىتواند سبب ارتقاى خودكارآمدى دانشجويان

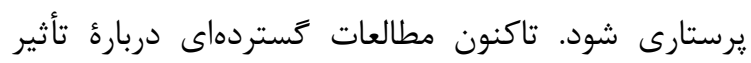

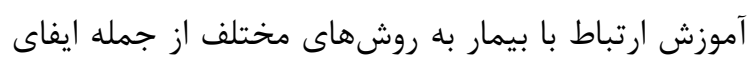

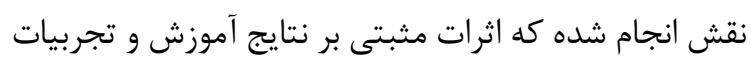

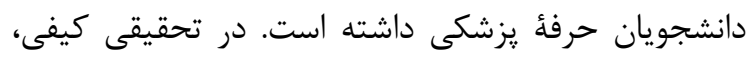

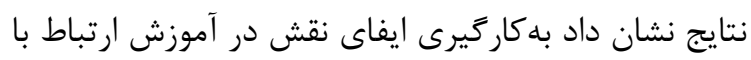

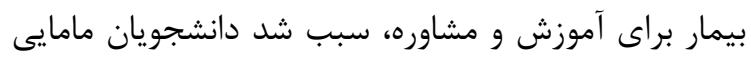
مراحل \ايفاى نقش بهطور نمايشى"، "ايفاى نقش بهطور

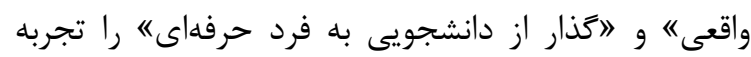

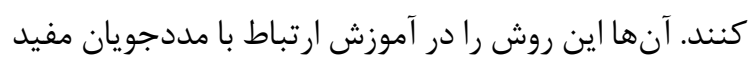

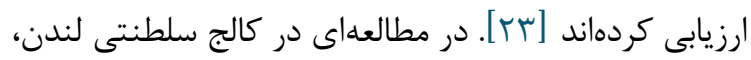

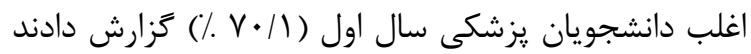

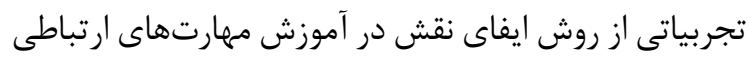
خود از قبيل ياد

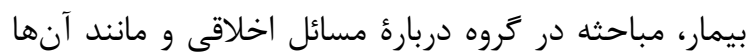

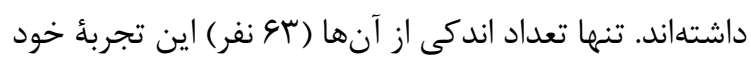

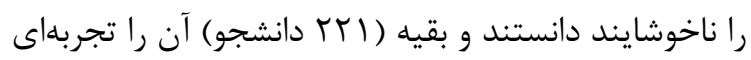

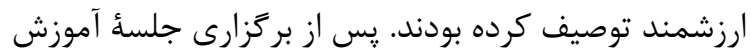


خودكارآمدى دانشجويان منجر شد. به همين لحاظ اين

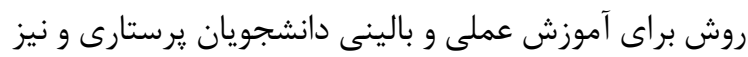

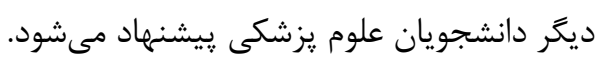

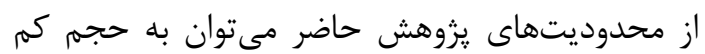

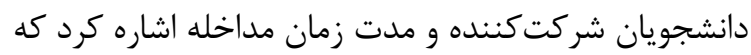
در طول يك دورة كارآموزى انجام شد. على درغم اينكه

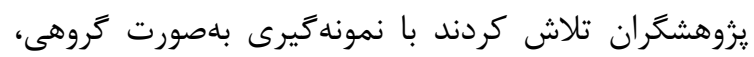
تصادفىسازى تخصيص گروههاى دانشجويى به دو گروه، و همجنين نمونه گيرى دانشجويان از دو نيمسال مختلف تحصيلى، از تماس دانشجويان گروه كنترل با گروه ايفاى نقش جلوگيرى كنند، هنوز احتمال تماس اين دو گروه به دليل همزمانى تحصيل در يك دانشكده وجود داشت كه از

$$
\text { كنترل يزوهشخر خارج بود. }
$$

$$
\text { سياسخزارى }
$$

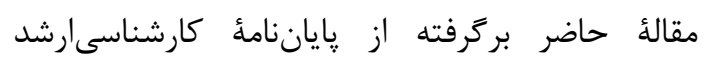
يرستارى داخلى - جراحى است كه از سوى معاونت محترم

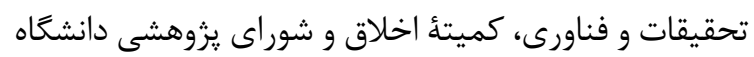

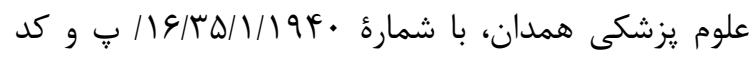

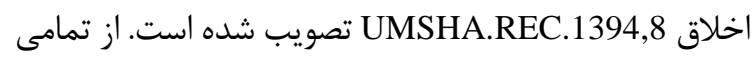
دانشجويان و اساتيد محترم و مسئول يراتيك دانشكدء يرستارى و مامايى كه ما رادر انجام اين مطالعه يارى كردند،

$$
\text { تشكر و قدردانى مى كنيم. }
$$

بين نويسندگًان هيجزَّه تعارضى در منافع وجود ندارد

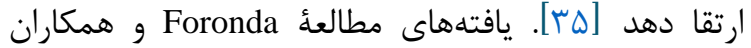

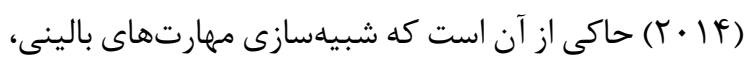
باعث افزايش قابلتوجهى در مهارتهاى ارتباطى دانشجويان مىشود [عب]. در بعد خودكارآمدى، در تأييد نتايج مطالعهُ حاضر، Shinnick نقش با استفاده از شبيهساز بيمارنما، سبب افزايش دائ قابلتوجهى در نمرات خودكارآمدى دانشجويان يرستارى گروه مداخله شده است [rV] Merriman

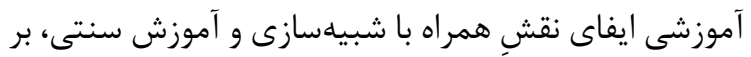

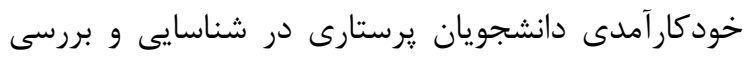
بيماران بدخيم انجام شد، نشان داد نمرات خود كار آمدى بعد دئن

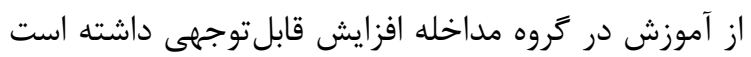

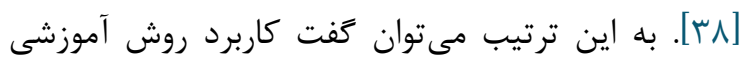
ايفاى نقش در آموزش وظايفى مؤثر است كه مهارتهاى

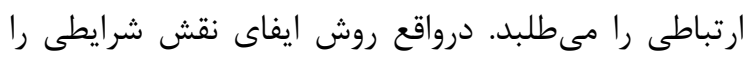

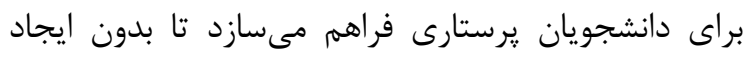

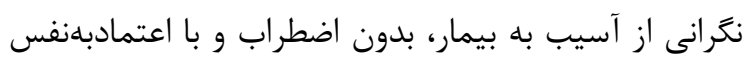

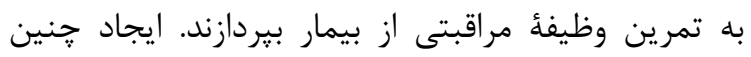

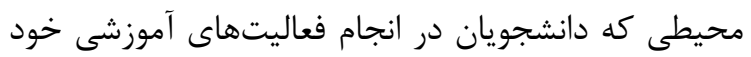

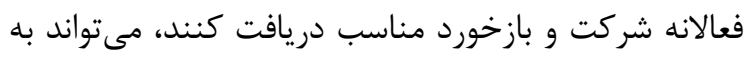
افزايش خودكارآمدى دانشجويان يرستارى منجر شود.

$$
\text { نتيجه تيرى }
$$

نتايج اين مطالعه، اثربخش بودن آموزش بهروش ايفاى

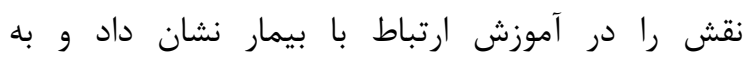

\section{References}

1. Riley JB. Communication in nursing. United States: Elsevier Health Sciences; 2015.

2. Malt G. Cochrane Review Brief: Interprofessional Education: Effects On Professional Practice and Healthcare Outcomes. Online journal of issues in nursing. 2015;20(2):12.

3. Utley-Smith Q. 5 competencies needed by new baccalaureate graduates. Nursing Education Perspectives. 2004;25(4):166-70.
4. Meleis AI. Theoretical nursing: Development and progress: Lippincott Williams \& Wilkins; 2011.

5. Khatami S, Asefzadeh S. Communication skills of medical interns of Qazvin UMS. The Journal of Qazvin University of Medical Sciences. 2007;11(3):79-81.

6. Vancheri C. Innovations in health literacy research: workshop summary: National Academies Press; 2011. 
7. Arnold EC, Boggs KU. Interpersonal RelationshipsE-Book: Professional Communication Skills for Nurses: Elsevier Health Sciences; 2015.

8. Arfaie K. Priorities of clinical education evaluation from nursing and midwifery students' perspective. Iran Journal of Nursing. 2012;25(75):71-7.

9. Mirzaei-Alavijeh M, Motlagh M, Hosseini S, Jalilian F. Nursing Students Communication Skills with Patients in Kermanshah University of Medical Sciences. Research in Medical Education. 2017;9(3):54-47.

https://doi.org/10.29252/rme.9.3.54

10. Adib Hajbaghery M, Rezaei Shahsavarloo Z. Assessing the nursing and midwifery students competencies in communication with patients with severe communication problems. Nurs Midwifery Stud.

https://doi.org/10.5812/nms.18143

PMID:25414902

11. Kiani F, Balouchi A, Shahsavani A. Investigation of nursing students' verbal communication quality during patients' education in zahedan hospitals: Southeast of Iran. Global journal of health science. 2016;8(9):331.

https://doi.org/10.5539/gjhs.v8n9p331

PMID:27157186

12. Rostami H, Golchin M, Mirzaei A. Evaluation of communication skills of nurses from hospitalized patients'perspective. Journal of Urmia Nursing and Midwifery Faculty. 2012;10(1)

13. Papastavrou E, Lambrinou E, Tsangari H, Saarikoski M, Leino-Kilpi H. Student nurses experience of learning in the clinical environment. Nurse Education in Practice. 2010;10(3):176-82. https://doi.org/10.1016/j.nepr.2009.07.003 PMID:19700368

14. Managheb S, Firouzi H, Jafarian J. The impact of communication skills training based on calgarycambridge guideline on knowledge, attitude and practice of family physicians in jahrom university of medical sciences 2007. 2008.

15. Ranse K, Grealish L. Nursing students' perceptions of learning in the clinical setting of the Dedicated Education Unit. Journal of Advanced Nursing. 2007;58(2):171-9.

https://doi.org/10.1111/j.1365-2648.2007.04220.x PMID:17445020

16. Colletti L, Gruppen L, Barclay M, Stern D. Teaching students to break bad news. The American Journal of Surgery. 2001;182(1):20-3. https://doi.org/10.1016/S0002-9610(01)00651-1

17. Billings DM. Role-play revisited. Journal of continuing education in nursing. 2012;43(5):201-2. https://doi.org/10.3928/00220124-20120424-04 PMID:22582956

$$
\text { ع ع تأثير آموزش مهارتهاى ارتباط با بيمار... }
$$

18. Nestel D, Tierney T. Role-play for medical students learning about communication: Guidelines for maximising benefits. BMC Medical Education. 2007;7:3-.https://doi.org/10.1186/14726920-7-3 PMID:17335561 PMCid:PMC1828731

19. Khatiban M, Sangestani G. The effects of using problem-based learning in the clinical nursing education on the students' outcomes in Iran: A quasi-experimental study. Nurse education in practice. 2014;14(6):698-703. https://doi.org/10.1016/i.nepr.2014.10.002 PMID:25458229

20. Sangestani G, Khatiban M. Comparison of problem-based learning and lecture-based learning in midwifery. Nurse Educ Today. 2013;33(8):7915. https://doi.org/10.1016/j.nedt.2012.03.010 PMID:22503681

21. Karbasi F, khatiban M, Soltanian A. The Effect of Teaching Nurse-patient Communication through Role-play Method on Nursing Students' Caring Behaviors: A Quasi-Experimental Study. Iranian Journal of Medical Education. 2016;16:120-30.

22. Khatiban M, Sangestani G, Bennet N, Oshvandi K. Role-playing versus conventional strategy in midwifery clinical education on breast selfexamination: A quasi-experimental study. Journal of Clinical and Diagnostic Research. 2017;11(12):JC01-JC6. https://doi.org/10.7860/JCDR/2017/29334.10931

23. Khatiban M, Sangestani G, Oshvandi K. Midwifery students' experience of role-playing as a teaching strategy: a qualitative study. Journal of Nursing Education. 2014;3(1):61-70.

24. Hsu L-L, Chang W-H, Hsieh S-I. The effects of scenario-based simulation course training on nurses' communication competence and selfefficacy: a randomized controlled trial. Journal of Professional Nursing. 2015;31(1):37-49. https://doi.org/10.1016/j.profnurs.2014.05.007 PMID:25601244

25. Yip MP, Ong BN, Meischke HW, Feng SX, Calhoun R, Painter I, et al. The role of self-efficacy in communication and emergency response in Chinese limited english proficiency (LEP) populations. Health promotion practice. 2013;14(3):400-7.

https://doi.org/10.1177/1524839911399427

PMID:21460258

26. Sung SC, Huang HC, Lin MH. Relationship between the knowledge, attitude, and self-efficacy on sexual health care for nursing students. Journal of professional nursing: official journal of the American Association of Colleges of Nursing. 2015;31(3):254-61.https://doi.org/10.1016 /i.profnurs.2014.11.001PMID:25999199 
27. Bandura A. Self-efficacy: toward a unifying theory of behavioral change. Psychological review. 1977;84(2):191.https://doi.org/10.1037/0033295X.84.2.191 PMID:847061

28. Andrew S, McVicar A, Zanganeh M, Henderson N. Self-efficacy and relevance of bioscience for nursing, midwifery and healthcare students. J Clin Nurs. 2015;24(19-20):2965-72. https://doi.org/10.1111/jocn.12933 PMID:26238000

29. Lent RW, Schmidt J, Schmidt L. Collective efficacy beliefs in student work teams: Relation to self-efficacy, cohesion, and performance. Journal of Vocational Behavior. 2006;68(1):73-84. https://doi.org/10.1016/j.jvb.2005.04.001

30. Hagemeier NE, Hess R, Jr., Hagen KS, Sorah EL. Impact of an interprofessional communication course on nursing, medical, and pharmacy students' communication skill self-efficacy beliefs. Am J Pharm Educ. 2014;78(10):186. https://doi.org/10.5688/ajpe7810186 PMID:25657373 PMCid:PMC4315208

31. Joolaee S, Hajibabaee F, Jafar Jalal E, Bahrani N. Assessment of patient satisfaction from nursing care in hospitals of Iran University of Medical Sciences. Hayat. 2011;17(1):35-44.

32. Sherer M. The self-efficacy scale: Construction and Validation. Psychological Reports. 1982;51(2):663-71.

https://doi.org/10.2466/pr0.1982.51.2.663

33. Vizeshfar F, Dehghanrad F, Magharei M, Sobhani SMJ. Effects of Applying Role Playing Approach on Nursing Students' Education. International Journal of Humanities and Cultural Studies (IJHCS) ISSN 2356-5926. 2016:1772-81.

34. Kesten KS. Role-play using SBAR technique to improve observed communication skills in senior nursing students. Journal of Nursing Education. 2011;50(2):79-87.

https://doi.org/10.3928/01484834-20101230-02 PMID:21210611

35. Ahsen NF, Batul SA, Ahmed AN, Imam SZ, Iqbal $\mathrm{H}$, Shamshair K, et al. Developing counseling skills through pre-recorded videos and role play: a pre-and post-intervention study in a Pakistani medical school. BMC Medical Education. 2010;10(1):7. https://doi.org/10.1186/1472-692010-7 PMID:20102626 PMCid:PMC2837024
36. Foronda C, Gattamorta K, Snowden K, Bauman E. Use of virtual clinical simulation to improve communication skills of baccalaureate nursing students: A pilot study. nurse education today. 2014;34(6):53-7. https://doi.org/10.1016 /j.nedt. 2013.10.007 PMID:24231637

37. Shinnick MA, Woo MA. Does Nursing Student Self-efficacy Correlate with Knowledge When Using Human Patient Simulation? Clinical Simulation in Nursing. 2014;10(2):e71-9. https://doi.org/10.1016/j.ecns.2013.07.006

38. Merriman CD, Stayt LC, Ricketts B. Comparing the effectiveness of clinical simulation versus didactic methods to teach undergraduate adult nursing students to recognize and assess the deteriorating patient. Clinical Simulation in Nursing. 2014;10(3):e119-27. https://doi.org/10.1016/j.ecns.2013.09.004 